\title{
Changes in the sexual health of obese patients after bariatric surgery
}

\author{
Cambios en la salud sexual de los pacientes obesos tras cirugía bariátrica
}

\author{
María A. Pomares-Callejón ${ }^{1 *}$, Manuel Ferrer-Márquez² and María J. Solvas-Salmerón ${ }^{3}$ \\ ${ }^{1}$ Department of Nursing, Physiotherapy and Medicine, Universidad de Almería; ${ }^{2}$ Department of General ad Digestive Surgery; ${ }^{3} E m e r g e n c y$ \\ Department. Complejo Hospitalario Torrecárdenas. Almería, Spain
}

\begin{abstract}
Introduction: The aims of the study were: 1) to assess sexual health patients severe/morbid obesity patients candidates for bariatric surgery; and 2) to assess sexual health evolution after 12 months of surgery. Method: Descriptive, prospective study from February 2011 to June 2014. Sexual activity in men was valued through EVAS-H questionnaire and through FSM scale on women (44 patients). Results: During the basal study in men, a $21 \%$ of the sample showed sexual disfunction in different dimensions, while a $43 \%$ showed problems with premature ejaculation. 12 months after surgery, global sexual activity was improved significantly $(p=0,026)$. Approximately $70-89 \%$ of women presented no disturbance before surgery. No average relevant changes were observed within the evolution $(p>0.05)$. Conclusions: Morbid/severe obesity patients candidates to bariatric surgery, show considerable alterations on diverse sexual health dimensions. After 12 months following bariatric surgery, men's sexual health appears to improve.
\end{abstract}

KEY WORDS: Obesity. Bariatric surgery. Sexual health. Sexual function.

\section{Resumen}

Introducción: Los objetivos del estudio fueron: 1) evaluar la salud sexual en pacientes con obesidad grave/mórbida candidatos a cirugía bariátrica; y 2) valorar la evolución de la salud sexual tras 12 meses de la cirugía. Método: Estudio descriptivo, prospectivo desde febrero de 2011 hasta junio de 2014. Se valoró la actividad sexual en los hombres a través del cuestionario EVAS-H y la función sexual en la mujer a través de la escala FSM (44 pacientes). Resultados: Durante el estudio basal en los hombres, un $21 \%$ de la muestra presentó disfunción sexual en diferentes dimensiones, mientras que un $43 \%$ presentó problemas de eyaculación precoz. Tras 12 meses de la intervención, se observó un incremento de la actividad sexual global ( $p=0.026)$. En torno al $70-89 \%$ de las mujeres, previamente a la cirugía, no presentaban trastorno. En la evolución no se observaron cambios medios relevantes $(p>0.05)$. Conclusiones: Los pacientes con obesidad grave/mórbida candidatos a cirugía bariátrica presentan alteraciones considerables en diversas dimensiones de la salud sexual. Después de 12 meses de seguimiento, la salud sexual parece mejorar en los hombres.

PALABRAS CLAVE: Obesidad. Cirugía bariátrica. Salud sexual. Función sexual.

\section{Correspondence:}

*María A. Pomares-Callejón

Avda. Mediterráneo, 388, 501 a

04009 Almería, España

E-mail: mpc630@ual.es
Date of reception: 09-03-2018

Date of acceptance: 11-04-2018

DOI: $10.24875 / C I R U E . M 18000039$
Cir Cir. 2018;86:226-231

Contents available at PubMed www.cirugiaycirujanos.com 


\section{Introduction}

Obesity represents a pathological process and a public health problem in the human being. This process has lived on for centuries due to genetic and environmental factors until, at present, having become a pandemic with serious consequences for health ${ }^{1,2}$.

Sexuality constitutes a basic function of the human being that involves physiological, emotional and cognitive factors, and that is closely related to health individual status and quality of life. Just as the potential impact various medical problems can have on sexual health is undeniable, there is also a generalized agreement on the determining role that some psychological processes can play in sexual functioning and in the development of different sexual dysfunctions ${ }^{3}$. Therefore, it is not surprising that sex life of patients with obesity can be significantly altered ${ }^{4-7}$. However, until very recently, the study of the impact of obesity on sexual health has been ignored, despite the fact that, in the last few years, several studies addressing this issue have emerged ${ }^{4,5,8,9}$.

Sexual dysfunction in obese patients is a common and complex disorder that can considerably affect the quality of life of patients. Steffen et al. ${ }^{10}$ and Bond et al. ${ }^{11}$ observed that women mainly attribute their lack of sexual activity to being tired, not interested or not having an available partner, while men attribute it mainly to physical difficulties. Different factors have been associated with sexual dysfunction in these patients, with the main ones being depressive problems and the related medication, physical problems and a large part of associated comorbidities (cardiovascular conditions, hypertension, diabetes mellitus) ${ }^{10,12,13}$. There are some works, very sparse yet, that have tried to study the effect of bariatric surgery on sexual response $e^{14-16}$.

The purposes of our study were: 1) to assess sexual health in patients with severe/morbid obesity who were candidates for bariatric surgery; and 2) to assess sexual health evolution 12 months after bariatric surgery.

\section{Method}

\section{Study design}

Descriptive, prospective study where the influence of bariatric surgery on the sexual health of patients with severe/morbid obesity who were candidates for surgical treatment and were consecutively intervened from February 2011 to June 2014, is analyzed.

The project was approved by the hospital ethics committee.

\section{Protocol for data collection}

All patients were assessed by a multidisciplinary team prior to surgical treatment. The patients were operated by the Bariatric Surgery Unit by performing a gastric bypass or laparoscopic vertical gastrectomy depending on the characteristics of each one and following the center protocols.

The inclusion criteria of the study were: being candidates for bariatric surgery with a body mass index $(\mathrm{BMI}) \geq 40 \mathrm{~kg} / \mathrm{m}^{2}$ or $\geq 35 \mathrm{~kg} / \mathrm{m}^{2}$ with associated comorbidity; age between 18 and 60 years; obesity maintained for more than 5 years; failure of other non-surgical treatments to solve obesity; and signing the informed consent to participate in the study.

Patients were admitted the day prior to the intervention. Upon admission, the personal interview was conducted and the study was explained to the participants, who then voluntarily and anonymously completed the Short Scale for the Evaluation of Sexual Activity in Men (EVAS-H - Escala Corta para la Evaluación de la Actividad Sexual en el Hombre) and Female Sexual Function (FSM - Función Sexual de la Mujer) questionnaires ${ }^{17,18}$ (for men and women, respectively). Similarly, after 12 months of follow-up, the patients were interviewed again in the surgery outpatient clinic and were invited to complete the same questionnaire.

\section{Variables and measuring instrument}

EVAS-H is a questionnaire designed to measure sexual activity in men. It consists of 10 items that measure different sexual dimensions. The cut-off point is 38 points and, below this value, it would indicate the presence of sexual dysfunction. In addition, it can be corrected for dimensions where scores $\leq 3$ would indicate the presence of dysfunction ${ }^{17}$. FSM evaluates sexual function in women and it is a self-administered scale consisting of 14 items, after a key question. The reliability of this questionnaire has a Cronbach's alpha of 0.83 and it assesses different sexual dimensions ${ }^{18}$.

Among the rest of the studied variables, weight, $\mathrm{BMI}$, the presence of comorbidity, the type of surgical 
intervention and the percentage of excess BMI lost stand out.

\section{Statistical analysis}

Descriptive statistics were carried out, with the results being presented as means and standard deviations for quantitative variables, and as numbers and percentages for qualitative variables. A normality analysis was conducted for the main study variables, such as weight, and for sexuality variables using a histogram and the Shapiro Wilk test.

To assess sexual health, descriptive statistics (for men and women separately, as well as for the entire sample as a whole) of the EVAS-H and FSM questionnaires were carried out. Sexual health evolution was assessed by means of linear regression adjusted for age, baseline BMI and marital status for quantitative variables, and the McNemar test was used for qualitative variables (since the samples were small, the significance value was calculated using the exact binomial test).

\section{Results}

Between February 2011 and June 2014, 60 patients were intervened and, hence, were invited to participate in the study. Of them, 16 were not interested, and thus 44 patients were included (28 women and 16 men). Mean age was 40 years, and mean BMI was $46.8 \mathrm{~kg} / \mathrm{m}^{2}$. Comorbidity was present throughout the study, with the most common being obstructive sleep apnea syndrome (OSAS), at a percentage of $88.9 \%$.

Twelve months after the intervention, patients had experienced a significant reduction in BMI, from a mean of 46.8 to $31.7 \mathrm{~kg} / \mathrm{m}^{2}(p<0.001)$. Regarding comorbidity, there was a significant reduction in OSAS, dyslipidemia and hypertension. Metabolic syndrome disappeared and the figures of patients with diabetes mellitus were substantially decreased (Table 1).

In the baseline assessment, EVAS-H scale mean scores do not indicate, in general, presence of sexual dysfunction, since the questionnaire total score mean value was 42 points. However, $21 \%$ of the study sample had values lower than 38 points. On the other hand, neither did mean values per dimension indicate dysfunction (mean scores $>3$ ), except in the case of premature ejaculation, with a mean score of 2.67. In this sense, $21 \%$ of the sample showed sexual dysfunction in the desire, erectile function and
Table 1. Changes in weight, body mass index and different clinical variables related to cardiovascular risk in patients with severe/ morbid obesity 12 months after bariatric surgery intervention

\begin{tabular}{lcccccc}
\hline & \multicolumn{2}{c}{ Pre } & & \multicolumn{2}{c}{ Post } & p \\
\cline { 2 - 3 } & Mean & SD & & Mean & SD & \\
\hline Weight, $\mathrm{kg}$ & 133.9 & 22.6 & 88.6 & 15.7 & $<0.001$ \\
BMl $\left(\mathrm{kg} / \mathrm{m}^{2}\right)$ & 46.8 & 7.1 & 31.7 & 6.7 & $<0.001$ \\
Comorbidity & & $\%$ & & $\%$ & \\
Metabolic syndrome & & 11.1 & & 0.0 & - \\
Hypertension & & 33.3 & & 7.4 & 0.016 \\
Diabetes mellitus & & 25.9 & & 11.1 & 0.125 \\
Dyslipidemia & & 37.0 & & 3.7 & 0.004 \\
OSAS & & 88.9 & & 7.4 & $<0.001$ \\
\hline
\end{tabular}

BMI: body mass index; OSAS: obstructive sleep apnea syndrome; SD: standard deviation.

satisfaction dimensions, while $43 \%$ had premature ejaculation problems.

Twelve months after the intervention, an increase was observed in all EVAS-H scale dimensions, although this increase was not statistically significant. Overall sexual activity was significantly increased after the intervention (mean increase: 8.7 units, $p=0.026)$. This increase might be due, in part, to an increase in the mean erectile function score, which, in spite of not being significant, showed a clear trend (mean increase: 4.5 units, $p=0.058$ ) (Table 2).

When analyzing the changes in overall sexual dysfunction, as well as the corresponding dysfunction by dimensions, although there was a smaller number of patients with sexual dysfunction in most dimensions, the differences were observed not to be significant.

The results related to sexual function in women showed that in the desire, arousal, initiative, communication and satisfaction dimensions (sexual activity and general sexuality), around $70-89 \%$ of women had no disorders. In addition, 31\% reported having sexual activity once or twice weekly and $31 \%$ reported having sexual activity between five and eight times weekly in the previous 4 weeks. However, the existence of a significant lubrication disorder could be observed in $15 \%$ of the sample, a moderate or significant orgasm disorder in 4 and $12 \%$, respectively, a high percentage (58\%) of moderate disorder in vaginal penetration problems, and $73 \%$ of important disorder in anticipatory anxiety.

Mean score evolution of the different dimensions of sexual function of women is presented in table 3 . No relevant changes were observed in any sexual function dimension ( $p>0.05$ ). 
Table 2. Evolution of EVAS-H scale responses mean and standard deviation at baseline and at 12 months of follow-up in males with severe/morbid obesity who underwent bariatric surgery

\begin{tabular}{lcccccccc}
\hline EVAS-H & \multicolumn{2}{c}{ Pre } & & \multicolumn{2}{c}{ Post } & & p \\
\cline { 2 - 3 } & Mean & SD & & Mean & SD & \\
\hline Desire (range: 2-10) & 6.3 & 3.1 & 8.0 & 2.8 & 0.270 \\
Erectile function (range: 4-20) & 15.0 & 6.3 & 19.5 & 1.4 & 0.058 \\
Premature ejaculation (range: 2-10) & 5.3 & 2.6 & 6.0 & 2.4 & 0.556 \\
Orgasm (range: 1-5) & 4.3 & 0.9 & 4.5 & 1.1 & 0.619 \\
Satisfaction (range: 2-10) & 6.8 & 2.4 & 7.9 & 2.1 & 0.343 \\
Pain (range: 1-5) & 4.6 & 0.7 & 4.9 & 0.4 & 0.423 \\
Total score (0-60) & 42.1 & 7.7 & 50.8 & 5.9 & 0.026 \\
\hline SD: standard deviation. & & & & & &
\end{tabular}

\section{Discussion}

Obesity has become the $21^{\text {st }}$ century epidemic, with important repercussions for the health of the individual who suffers from it. As part of it, sexual health and different domains of sexuality can be altered in this type of patients. In the present study, erectile dysfunction was observed in $21 \%$ of men, which is consistent with previous studies ${ }^{6,19-22}$ that show prevalences of erectile dysfunction ranging from 12 to $36 \%$. Moreira et al. ${ }^{20}$, in 2000, in a sample of 342 men, detected erectile dysfunction in $12 \%$. However, both Fung et al. ${ }^{19}$ and Cheng et al. ${ }^{21}$ found higher rates of erectile dysfunction (36 and $36.7 \%$, respectively), with large sample sizes and using the International Index of Erectile Function (IIEF) questionnaire.

On the other hand, the high percentage of men with premature ejaculation at baseline should be noted, which is in line with the study by Dallal et al. findings ${ }^{23}$, where, using the Brief Sexual Function Inventory (BSFI) questionnaire, found significantly lower ejaculatory function scores than those of the general population. These results highlight the importance of assessing other sexuality dimensions in men with morbid obesity, in addition to erectile function.

With regard to female sexual function, the high percentages of moderate vaginal penetration disorder (58\%) should be mentioned, which was possibly influenced by the $15 \%$ rate observed for important lubrication problems, as well as by the high percentage of women with severe anticipatory anxiety disorder (73\%). The rates for other female sexuality alterations, such as desire, arousal and orgasm disorders, were in the vicinity of $15 \%$, when pooling the rates of
Table 3. Mean evolution of FSM questionnaire responses at baseline and at 12 months of follow-up in women with severe/ morbid obesity who underwent bariatric surgery

\begin{tabular}{|c|c|c|c|c|c|}
\hline \multirow[t]{2}{*}{ FSM } & \multicolumn{2}{|c|}{ Pre } & \multicolumn{2}{|c|}{ Post } & \multirow[t]{2}{*}{ p } \\
\hline & Mean & SD & Mean & SD & \\
\hline Desire (range: 1-15) & 10.6 & 2.5 & 10.8 & 3.4 & 0.850 \\
\hline $\begin{array}{l}\text { Arousal } \\
\text { (range: 1-15) }\end{array}$ & 11.4 & 3.3 & 11.3 & 3.2 & 0.721 \\
\hline $\begin{array}{l}\text { Lubrication } \\
\text { (range: } 1-15 \text { ) }\end{array}$ & 3.8 & 1.4 & 3.6 & 1.6 & 0.893 \\
\hline $\begin{array}{l}\text { Orgasm } \\
\text { (range: } 1-5 \text { ) }\end{array}$ & 4.6 & 1.0 & 4.5 & 1.1 & 0.617 \\
\hline $\begin{array}{l}\text { Vaginal penetration } \\
\text { problems } \\
\text { (range: } 1-15)\end{array}$ & 7.1 & 1.8 & 7.9 & 1.9 & 0.230 \\
\hline $\begin{array}{l}\text { Anticipatory anxiety } \\
\text { (range: 1-5) }\end{array}$ & 1.5 & 1.2 & 1.4 & 0.9 & 0.848 \\
\hline $\begin{array}{l}\text { Sexual initiative } \\
(1-5)\end{array}$ & 3.2 & 1.2 & 2.9 & 0.8 & 0.696 \\
\hline $\begin{array}{l}\text { Sexual } \\
\text { communication } \\
\text { (range: } 1-5)\end{array}$ & 3.9 & 1.4 & 4.3 & 1.1 & 0.495 \\
\hline $\begin{array}{l}\text { Satisfaction with } \\
\text { sexual activity } \\
\text { (range: } 1-10)\end{array}$ & 9.3 & 1.3 & 9.1 & 2.1 & 0.688 \\
\hline $\begin{array}{l}\text { General sexual } \\
\text { satisfaction } \\
\text { (range: } 1-10)\end{array}$ & 4.1 & 0.7 & 4.3 & 1.2 & 0.854 \\
\hline
\end{tabular}

moderate and severe disorder, which is a percentage somewhat lower than in most previous studies.

In 2014, Janik et al. ${ }^{24}$ published a cross-sectional study where a series of 153 women answered the Female Sexual Function Index (FSFI) and Sexual Quality of Life-Female (SQoL-F) questionnaires. The results obtained in the preoperative period according to FSFI showed that 10 out of every 20 women $(50 \%)$ had sexual dysfunction. They concluded that obesity reduces the quality of life, including sexual quality, since it causes specific sexual problems, including decreased sexual desire and a lower frequency of sexual encounters ${ }^{24,25}$.

Jiménez et al. ${ }^{26}$, in 2014, used the FSM questionnaire in 50 female candidates to bariatric surgery. Their results with regard to lubrication disorders are similar to those obtained in our study (12.5\%). As for vaginal penetration problems and anticipatory anxiety, their percentages were much lower (12.5 and 6.25\%, respectively).

After 12 months' follow-up, an improvement in sexual activity was observed in men, judging by an increase 
of nearly nine units (15\%) in the EVAS-H scale overall score. The results showed that this increase was due in part to the erectile function higher score (4.5-units difference from baseline), although the rest of the questionnaire dimensions also increased their score (but not significantly). Lobató et al. ${ }^{27}$, in their 2011 qualitative/quantitative study, after a follow-up period of 12 months after gastric bypass surgery, demonstrated an improvement in the desire, erectile function and orgasm domains, which is in line with the present results. In 2012, Goitein et al..$^{25}$ carried out a study in women and men with morbid obesity and who underwent laparoscopic vertical gastrectomy and gastric bypass surgery. The FSFI questionnaire was used in women and BSFI in men, before and 6-7 months after surgery. After surgery, the BSFI score increased from 40.2 to 43.9 , but no statistical significance was reached. However, even when that difference was not found, there was an improvement in the general satisfaction, desire and erection dimensions, which is comparable to that established in our results, which are similar except for the fact that we did find significant differences in sexual activity overall score between before and after the intervention.

Taken together, these results indicate that sexual activity in men can considerably improve after bariatric surgery, which has great clinical and public health importance, and reinforces the benefits of said surgery as the first line of treatment for serious/morbid obesity. However, further research is needed to determine longterm effects (2-5 years), as well as the specific dimensions where improvements are particularly produced.

Female sexual function different dimensions, judging by the follow-up results using the FSM questionnaire, showed no significant differences after surgery. In 2010, Assimakopoulos et al. ${ }^{8}$, in a sample of 59 women, using the FSFI, concluded that all sexual domains were improved 1 year after surgery in women with obesity, except for anxiety and orgasm. Furthermore, in the statistical analysis, both BMI and the desire, arousal, lubrication, satisfaction and sexual function dimensions showed a significant improvement, which are similar results to those obtained by Janik et al.24, who revealed that, 12-18 months after surgery, the FSFI results for the desire and arousal domains were higher after the operation.

Moreover, Bond et al. ${ }^{11}, 6$ months after the surgical intervention, found that $22 \%$ still had sexual dysfunction, just as it occurs in our results, although they found an improvement in all domains except for desire and lubrication.
The study has limitations that should be pointed out. First, the sample size was relatively small, although it should be noted that most studies on sexuality in this population are not on large samples $9,11,24,26-29$. On the other hand, the included patients underwent surgery using two different surgical techniques whose results in terms of weight tend to vary, which may have affected the assessment of the association between weight loss and sexual health changes during follow-up.

In conclusion, patients with severe/morbid obesity who are candidates for bariatric surgery have considerable alterations in various dimensions of sexual health. After 12 months of post-bariatric surgery follow-up, men and women had differentiated results. On one hand, men's overall sexual activity was significantly improved, possibly driven by an improvement in erectile function, which requires further research. On the other hand, sexual function in women did not change after 12 months of follow-up.

\section{Ethical responsibilities}

Protection of people and animals. The authors declare that no experiments on humans or animals were conducted for this research.

Confidentiality of data. The authors declare having followed the protocols of their work center on the publication of patient data.

Right to privacy and informed consent. The authors have obtained informed consent of the patients or subjects referred to in the article. This document is in the possession of the corresponding author.

\section{Conflicts of interest}

The authors declare not having any conflicts of interest.

\section{References}

1. González E. Obesity: etiologic and pathophysiological analysis. Endocrinol Nutr. 2013;60:17-24. (Consultado el 10 de enero de 2018.) Disponible en http://www.sciencedirect.com/science/article/pii/S2173509313000081.

2. Cuesta AL, Sabán J. La obesidad como entidad pluripatológica. Epidemiología. Sistemas neurohormonales. En: Sabán J, editor. Madrid: Díaz de Santos; 2012. p. 246-52.

3. Carrobles J, Gámez M, Almendro C. Funcionamiento sexual, satisfacción sexual y bienestar psicológico y subjetivo en una muestra de mujeres españolas. An Psicol. 2011;27:27-34.

4. Kolotkin RL, Zunker C, Østbye T. Sexual functioning and obesity: a review. Obesity. 2012;20:2325-33.

5. Larsen SH, Wagner G, Heitmann BL. Sexual function and obesity. Int J Obes. 2007;31:1189-98.

6. Bajos N, Wellings K, Laborde C, Moreau C. Sexuality and obesity, a gender perspective: results from French national random probability survey of sexual behaviours. BMJ. 2010;340:c2573. 
7. Carr D, Murphy LF, Batson HD, Springer KW. Bigger is not always better: the effect of obesity on sexual satisfaction and behavior of adult men in the United States. Men Masc. 2013;16:452-77.

8. Assimakopoulos K, Karaivazoglou K, Panayiotopoulos S, Hyphantis T Iconomou G, Kalfarentzos F. Bariatric surgery is associated with reduced depressive symptoms and better sexual function in obese female patients: a one-year follow-up study. Obes Surg. 2011;21:362-6.

9. Efthymiou V, Hyphantis T, Karaivazoglou K, Gourzis P, Alexandrides TK Kalfarentzos $F$, et al. The effect of bariatric surgery on patient HRQOL and sexual health during a 1-year postoperative period. Obes Surg. 2015;25:310-8.

10. Steffen KJ, King WC, White GE, Subak LL, Mitchell JE, Courcoulas AP, et al. Sexual functioning of men and women with severe obesity before bariatric surgery. Surg Obes Relat Dis. 2017;13:334-43.

11. Bond DS, Wing RR, Vithiananthan S, Sax HC, Roye GD, Ryder BA, et al Significant resolution of female sexual dysfunction after bariatric surgery. Surg Obes Relat Dis. 2011;7:1-7

12. Assimakopoulos K, Panayiotopoulos S, Iconomou G, Karaivazoglou K, Matzaroglou $\mathrm{C}$, Vagenas $\mathrm{K}$, et al. Assessing sexual function in obese women preparing for bariatric surgery. Obes Surg. 2006;16:1087-91.

13. Trischitta V. Relationship between obesity-related metabolic abnormalities and sexual function. J Endocrinol Invest. 2003:26:62-4.

14. Camps MA, Zervos E, Goode S, Rosemurgy AS. Impact of bariatric surgery on body image perception and sexuality in morbidly obese patients and their partners. Obes Surg. 1996;6:356-60.

15. Kinzl JF, Trefalt E, Fiala M, Hotter A, Biebl W, Aigner F. Partnership, sexuality, and sexual disorders in morbidly obese women: consequences of weight loss after gastric banding. Obes Surg. 2001;11:455-8.

16. Sarwer DB, Lavery M, Spitzer JC. A review of the relationships between extreme obesity, quality of life, and sexual function. Obes Surg 2012;22:668-76.

17. Águila E, Sánchez L, Daza MT, La Calle P, Fernández I. Disfunciones sexuales en pacientes con DCA: estudio exploratorio descriptivo con el cuestionario EVAS-M y EVAS-H. Congreso Español de Sexología, V Encuentro Iberoamericano de Profesionales de la Sexología; 2010.
18. Sánchez F, Pérez M, Borrás JJ, Gómez O, Aznar J, Caballero A. Diseño y validación del Cuestionario de Función Sexual de la Mujer (FSM). Aten Primaria. 2004;34:286-92.

19. Fung MM, Bettencourt R, Barret-Connor E. Heart disease risk factors predict erectile dysfunction 25 years later: the Rancho Bernardo Study. J Am Coll Cardiol. 2004;43:1405-11.

20. Moreira ED, Bestane WJ, Bartolo EB, Fittipladi JA. Prevalence and determinants of erectile dysfunction in Santos, southeastern Brazil. Sao Paulo Med J. 2002;120:49-54.

21. Cheng JY, Ng EM. Body mass index, physical activity and erectile dysfunction: an U-shaped relationship from population-based study. Int $J$ Obes. 2007;31:1571-8.

22. Han TS, Tajar A, O'Neill TW, Jiang M, Bartfai G, Boonen S, et al. Impaired quality of life and sexual function in overweight and obese men: the European Male Ageing Study. Eur J Endocrinol. 2011;164:1003-11.

23. Dallal RM, Chernoff A, O'Leary MP, Smith JA, Braverman JD, Quebbemann BB. Sexual dysfunction is common in the morbidly obese male and improves after gastric bypass surgery. J Am Coll Surg. 2008;207:859-64.

24. Janik MR, Bielecka I, Paśnik K, Kwiatkowski A, Podgórska L. Female sexual function before and after bariatric surgery: a cross-sectional study and review of literature. Obes Surg. 2015;25:1511-7.

25. Goitein D, Zendel A, Segev L, Feigin A, Zippel D. Bariatric surgery improves sexual function in obese patients. IMAJ. 2015;17:616-9.

26. Jiménez C, Macías P, Pérez R, Cano A, Domínguez E. Impacto de la cirugía bariátrica en la función sexual de la mujer. BMI. 2014;4.5.8:5905. (Consultado el 20 de enero de 2018.) Disponible en: http://bmilatina. com/index.php/bmi/article/view/239

27. Lobató ML, Boccara MA, Germano D, Roberto P. Bariatric surgery: impact on sexuality of the obese person. Rev Col Bras Cir. 2014:41:412-20.

28. Esposito K, Ciotola M, Giugliano F, Bisogni C, Schisano B, Autorino R, et al. Association of body weight with sexual function in women. Int $J$ Impot Res. 2007;19:353-7.

29. Groutz A, Gordon D, Schachter P, Amir H, Shimonov M. Effects of bariatric surgery on male lower urinary tract symptoms and sexual function. Neurourol Urodyn. 2017;36:636-9. 